\title{
Tensile strength and impact resistance properties of materials used in prosthetic check sockets, copolymer sockets, and definitive laminated sockets
}

\author{
Maria J. Gerschutz, PhD; ${ }^{*}$ Michael L. Haynes, MS; Derek M. Nixon, BS; James M. Colvin, MS \\ The Ohio Willow Wood Company, Mt. Sterling, $\mathrm{OH}$
}

\begin{abstract}
Prosthetic sockets serve as the interface between people with amputations and their prostheses. Although most materials used to make prosthetic sockets have been used for many years, knowledge of these materials' properties is limited, especially after they are subjected to fabrication processes. This study evaluated tensile and impact properties of the current state-of-the-art materials used to fabricate prosthetic check sockets, copolymer sockets, and definitive laminated sockets. Thermolyn Rigid and Orfitrans Stiff check socket materials produced significantly lower tensile strength and impact resistance than polyethylene terephthalate glycol (PETG). Copolymer socket materials exhibited greater resistance to impact forces than the check socket materials but lower tensile strengths than PETG. The heated molding processes, for the check socket and copolymer materials, reduced both tensile strength and elongation at break. Definitive laminated sockets were sorted according to fabrication techniques. Nyglass material had significantly higher elongation, indicating a more ductile material than carbon-based laminations. Carbon sockets with pigmented resin had higher tensile strength and modulus at break than nonpigmented carbon sockets. Elongation at yield and elongation at break were similar for both types of carbonbased laminations. The material properties determined in this study provide a foundation for understanding and improving the quality of prosthetic sockets using current fabrication materials and a basis for evaluating future technologies.
\end{abstract}

Key words: amputee, carbon fiber, check socket, copolymer, definitive socket, diagnostic socket, elongation, impact resistance, laminate, materials, Orfitrans, PETG, prosthesis, prosthetic socket, tensile strength, Thermolyn.

\section{INTRODUCTION}

Prosthetic sockets serve as the connection between an amputee's residual limb and the prosthetic components that enable him or her to walk. The current selection of accepted prosthetic socket materials has been adopted historically without extensive characterization and/or evaluation. This is especially true regarding the effects of accepted fabrication processes on these materials. If one considers that the mechanical properties of prosthetic socket materials play a definitive role in limiting the possible quality of the resulting prosthetic sockets, this lack of material knowledge becomes significant. The lower-limb prosthetic suspension technologies currently available have significant limitations, including heat build-up [1] and unreliable reproduction of geometry [2]. Further, socket failures do occur. Anecdotal conversations with prosthetists often reveal rules of thumb for material choices and fabrication techniques. However, few, if any, of these practices are backed up by objective evaluations

\footnotetext{
Abbreviations: ANOVA $=$ analysis of variance, ASTM = American Society for Testing and Materials, CNC = computer numerically controlled, PETG = polyethylene terephthalate glycol. * Address all correspondence to Maria J. Gerschutz, PhD; The Ohio Willow Wood Company-Engineering, 15441 Scioto Darby Rd, PO Box 130, Mt. Sterling, OH 43143; 740-8693377; fax: 740-869-4374. Email: mariag@owwco.com DOI:10.1682/JRRD.2010.10.0204
} 
and the basis for these practices are not always passed down with the techniques. While this lack of a quantitative basis might make these trade practices tempting to dismiss, they are the result of hard-won knowledge that has quite literally been paid for with blood, sweat, and tears. Without some knowledge of the basic properties of the current materials and fabricated sockets, trying new methods or materials is not possible without risking the violation of some long-forgotten lesson of the past and potentially putting patients at risk. For these reasons, work on significant changes in the current state of the art needs to be predicted on some basic measures of the currently accepted performance levels of materials and sockets. Unfortunately, while significant effort and expense have been made to provide such a framework for other prosthetic components, no such standard exists for the most basic component in a lower-limb prosthetic: the socket. This lies in stark contrast to the generally held belief that the difference between a functional prosthetic device and a closet hanger is often a well-fitting and functional socket. This article is intended to be a first step in filling this void in the understanding of lower-limb prosthetic sockets. Also, as new materials and fabrication techniques emerge, it is important to verify that they provide a tangible benefit to the function and/or safety of the resulting prosthetic device. Knowledge of the mechanical properties of currently accepted prosthetic socket materials, before and after fabrication, will be necessary before one may compare and assess the advantages and disadvantages of new materials or processes as they become available.

Currently, various prosthetic socket materials are utilized depending on the socket's purpose. Diagnostic (or check) sockets, typically used for static or dynamic socket fit evaluation, are usually fabricated from thermoplastics. Some of the thermoplastics used in check socket construction include polyethylene terephthalate glycol (PETG) (also known as Vivak or NorthPlex), Thermolyn Rigid, and Orfitrans Stiff. Definitive (permanent) sockets can be made from thermoplastic or thermoset materials. A copolymer socket, constructed from a polypropylene copolymer, is an example of a thermoplastic permanent prosthetic socket. Laminated sockets are hybrid composites usually constructed from a thermoset resin and carbon fiber braid, but they may be fabricated from other lay-up materials like nyglass, nylon, cotton stockinette, or fiberglass.
Previous research on prosthetic socket materials has focused on laminate material. One study conducted by Taylor [3] used the American Society for Testing and Materials (ASTM) Standard 790-91 (flexural properties) and an axial compression test to evaluate laminate lay-ups of carbon fiber, fiberglass, and nyglass with the same epoxy resin. The study concluded that pure fiberglass material performed the worst in regards to flexural properties, followed by nyglass between two layers of carbon fiber [3]. The same researcher also analyzed fiber orientation, reporting tensile strengths for carbon fiber with epoxy resin ranging from 433 to $588 \mathrm{MPa}$ with a $0^{\circ} / 90^{\circ}$ orientation and tensile strength ranging from 12.2 to 46.8 MPa with a $\pm 45^{\circ} / 45^{\circ}$ orientation [4] per ASTM 3039. Another study, conducted by Phillips and Craelius [5], analyzed 24 combinations of prosthetic laminates and resins (8 lay-up materials and 3 types of resins). Specimens were tested per ASTM 3039. The study separated lay-ups into three ranges according to ultimate tensile strength. Perlon, nylon, cotton, nyglass, and spectralon were classified as low, with a range from 18 to $24 \mathrm{MPa}$. The middle classification consisted of fiberglass ranging from 67 to $109 \mathrm{MPa}$. Carbon was classified as high, with tensile strength values ranging from 236 to $249 \mathrm{MPa}$ [5]. An important note is that the carbon samples in the study were constructed in a $0^{\circ} / 90^{\circ}$ orientation, while the other materials were constructed in a $\pm 45^{\circ} / 45^{\circ}$ orientation. Reflection on the effects of orientation in Taylor's data (above) indicate that this discrepancy in orientation could have significantly affected the results [4] and bring the comparisons by Phillips and Craelius into serious question. Phillips and Craelius's bending results indicated a directly proportional trend between bending moment and the distance between carbon fibers [5]. Klasson provided stress and strain theories of laminate fibers; however, material testing was not presented [6].

Several publications discuss clinical experience with thermoplastics and the advantages and/or disadvantages of thermoplastics. However, these articles focused mostly on fabrication techniques; no material properties were investigated [7-9]. The only publicly available thermoplastic material properties found were those gathered from product information sheets. The product information sheets do not provide property specifications as a result of fabrication processes and do not provide an objective indication of their performance under low temperature conditions. Polymer materials typically exhibit a glass transition temperature below which they tend to be 
significantly more brittle. Prosthetic sockets are exposed to a variety of environmental conditions, including cold temperatures. Inclement weather may also increase the risk of the user falling, making the prosthetic socket more likely to sustain impact forces at the same time that the material properties might be compromised. This compound effect would make degraded performance of materials at low temperature a potential risk to patients. For this reason, an understanding of the effects of cold temperatures on prosthetic material properties is warranted so that materials that have such properties can be avoided in climates where lower temperatures are expected. A full evaluation of the glass transition temperature for a given polymer requires significant numbers of samples and was therefore beyond the scope of this work. However, an indication can be drawn by the performance at one lower temperature and data were collected at one such temperature.

We addressed this study from the perspective that understanding the properties of prosthetic socket materials is the foundation for understanding how to construct quality prosthetic sockets and provides a basis for evaluating future technologies. To address the apparent lack of basic materials information, this study analyzed the tensile strength and impact resistance of the current state-of-theart materials used in the construction of prosthetic sockets. Three types of prosthetic sockets were evaluated: check sockets, copolymer sockets, and definitive laminated sockets. This research evaluates all three types of sockets by analyzing material samples obtained from fabricated sockets and samples obtained from raw material specimens when applicable. Past research has primarily focused on specific configurations of definitive laminated sockets under controlled environments, concentrating on particular layups and resin combinations. This may not reflect the prosthetic field as a whole because prosthetic material properties can depend on the technique and individual technician. This study examined materials used in prosthetic sockets as they are constructed in the field. In this way, this study attempted to collect samples from a wide range of prosthetic facilities and provide information regarding the strength and variability of conventional socket materials and the effects of common practices.

\section{METHODS}

\section{Material Suppliers}

Both prosthetic sockets and raw materials were requested from nine prosthetic facilities. To obtain a sam- pling across the prosthetic field, we asked three facilities from each of three different types of facilities to supply materials for the study. The types of facilities included were central fabrication facilities, private practice facilities, and military facilities. Each facility was requested to supply four check sockets, a sheet of raw check socket material, four copolymer sockets, a sheet of raw copolymer material, and four definitive laminated sockets. To represent the facility's standard practice, type of material and fabrication methods were not restricted. Prosthetic sockets were constructed with a computer-aided design and computer-aided manufacturing electronic file using a generic transtibial residual-limb template from OMEGA ${ }^{\circledR}$ Tracer ${ }^{\circledR}$ (The Ohio Willow Wood Company; Mt. Sterling, Ohio) extrapolated to represent an anthropometric 98 percent male. The length from the patella tendon bar and the circumference at the patella tendon bar were $19.2 \mathrm{~cm}$ and $52.4 \mathrm{~cm}$, respectively. This provided a worst-case scenario for pulled sockets and also allowed for the incorporation of a flat popliteal area. After the sockets were received, tensile socket specimens were machined from this flat popliteal area, which is typically discarded after cutting the socket trim lines. The trimmed sockets were used for another study. The raw material tensile and impact specimens were directly removed from the flat sheet of raw material.

\section{Tensile Property Testing}

Tensile properties were tested according to the ASTM Standard D-638: Standard Test Method for Tensile Properties of Plastics [10]. The specimens from the prosthetic sockets and raw materials were computer numerically controlled (CNC)-machined according to Type V dimensions with thicknesses measured in order to calculate the original cross-sectional area. Dimensions and tolerances of the dumbbell-shaped specimens can be found in Figure 1. Thicknesses were specimen-dependent and the gauge length was $7.62 \pm 0.02 \mathrm{~mm}$. A total of six specimens was extracted from the socket material of each supplier (three in the horizontal direction and three in the vertical direction). The standard suggests a total of 10 specimens, 5 from each orientation. However, because of the limited material available for fabricating specimens, this number was reduced to six, three from each orientation. For consistency, only three specimens were extracted from the raw material in each orientation as well. Standard deviations were calculated and reported and allow for the effects of this reduced sample size. 
JRRD, Volume 48, Number 8, 2011

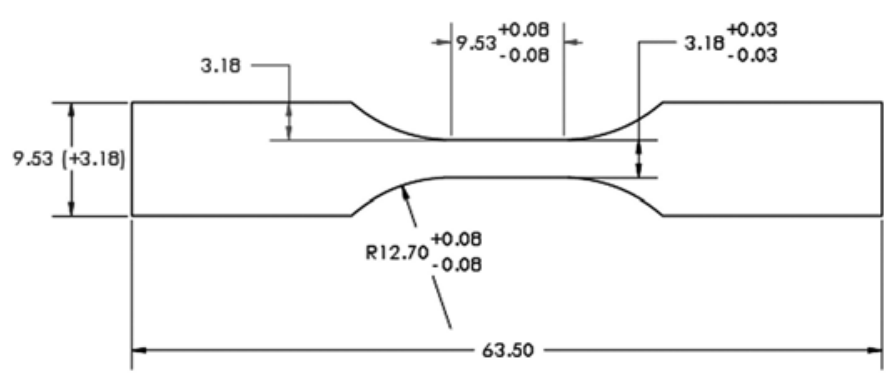

Figure 1.

Tensile specimen coupon dimensions and tolerances in millimeters.

Tensile tests were conducted on an Interlaken 3300 Series test frame with Series 3200 controller (Interlaken Technology Corporation; Chaske, Minnesota) in displacement control. Test rates were chosen so that the specimens ruptured between 30 and 300 s [10]. Preliminary testing indicated a test rate of $0.01905 \mathrm{~mm} / \mathrm{s}$ (0.00075 in./s) for the definitive laminated sockets and $0.381 \mathrm{~mm} / \mathrm{s}(0.015 \mathrm{in} . / \mathrm{s})$ for the check socket and copolymer materials. Speeds between normal rounded values were permitted to allow as many materials as possible to be tested at the same speed and still fall within the standard's allowable test time of 30 to 300 s. This common test speed allows for direct comparison between the thermoplastic materials. Tensile strength, modulus, percent elongation at yield, and percent elongation at break were calculated from the resulting force-displacement curve. Tensile strength was calculated by division of the maximum load by the original cross-sectional area in the gauge length segment. According to the maximum load location, tensile strength was indicated either as tensile strength at yield or tensile strength at break. Modulus was calculated by determination of the slope of the initial linear portion on the stress-strain curve. Percent elongation at yield was determined by division of the gauge displacement length at the yield point (from the forcedisplacement curve) by the originally specified gauge length and multiplication by 100 . The percent elongation at break was calculated by division of the gauge displacement length at the break point (from the force-displacement curve) by the originally specified gauge length and multiplication by 100 . Displacements were engineering displacements, i.e., machine displacement.

Check sockets were evaluated according to material type. Three types of materials were supplied: PETG (including Vivak), Thermolyn Rigid, and Orfitrans Stiff. A majority of the sockets were fabricated with the blister- forming method; however, two facilities used machinepulling methods.

Because copolymer sockets are, in theory, constructed from the same type of material, they were evaluated according to fabrication method. Three fabrication methods were used by the suppliers: blister-forming, draping, and machine-pulling. The raw machine-pulled material was provided as a bell-shaped mold instead of a flat sheet. A section was cut from the bell and heat flattened in an oven to allow test specimens to be fabricated.

Because definitive laminated sockets are composites, only the socket tensile specimens were evaluated. The definitive laminated sockets were analyzed according to fabrication technique. Not all the suppliers provided resin and construction lay-up information; therefore, the specimens were visually assessed and classified as carbon lamination with nonpigmented resin, carbon lamination with pigmented resin, or nyglass. The data were also separated according to the location of the tensile strength, either at yield or at break. Figure 2 illustrates the comparisons analyzed in this study.

\section{Impact Property Testing}

Charpy impact energy was tested according to the ASTM Standard D-6110: Standard Test Method for Determining the Charpy Impact Resistance of Notched Specimens of Plastics [11]. This standard essentially measures the energy needed to fully fracture a notched specimen by measuring the difference in height of a pendulum after it strikes the specimen halfway through a single swing. This difference in height is then displayed on a calibrated dial indicator. The test specimens were CNCmachined and notched according to the standard. The width of the specimen was measured for the calculation of impact properties. Three test specimens were CNCmachined from the check socket and copolymer raw material sheets. Testing was conducted on an Impact Tester-Izod Charpy Tension Impact (Testing Machines Inc; Amityville, New York).

The impact property testing was conducted at two temperature control settings: room temperature $\left(23^{\circ} \mathrm{C}\right)$ and freezer temperature $\left(-8{ }^{\circ} \mathrm{C}\right)$. The standard is only specified for the $23{ }^{\circ} \mathrm{C}$ temperature setting. However, the same test procedure was conducted in a cold environment because anecdotal evidence has indicated that temperature affects the properties of prosthetic socket materials. As mentioned earlier, if lower temperatures degrade impact properties, the risk of catastrophic socket failure 

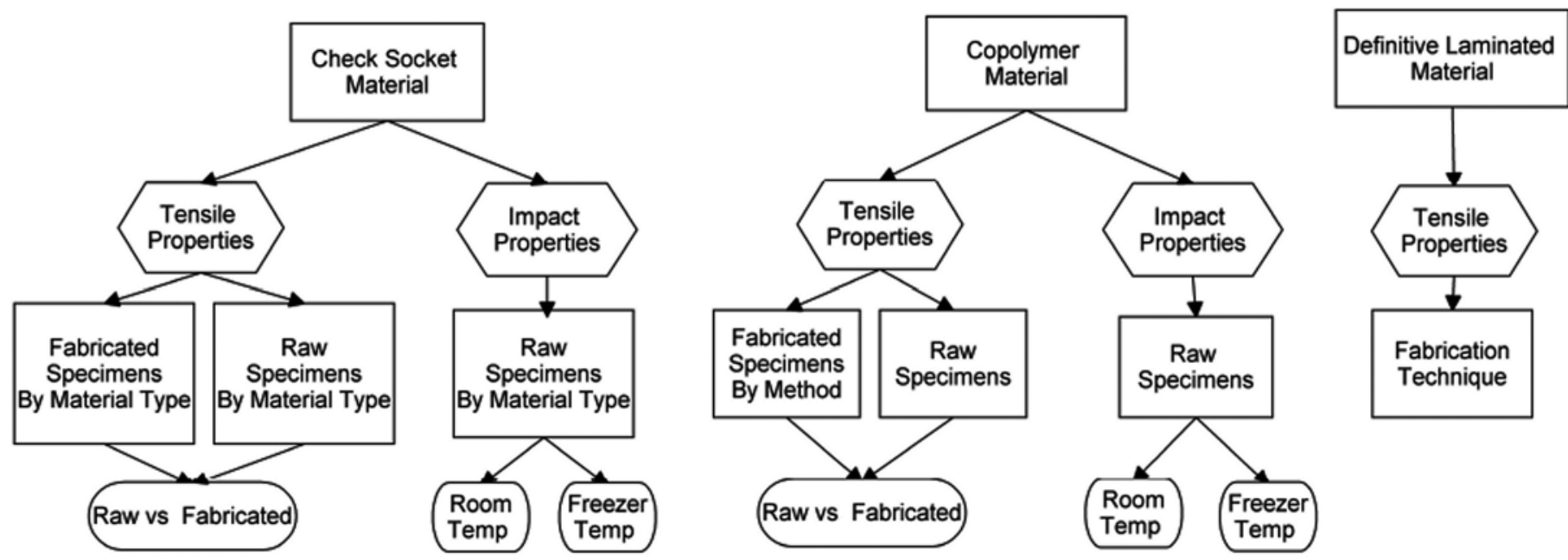

Figure 2.

Comparisons analyzed for check socket material, copolymer material, and definitive laminated material. Temp = temperature.

as a result of falling would increase. Specimens were conditioned for a minimum of $48 \mathrm{~h}$ at the specified temperature control settings before impact testing. During the test, temperature and humidity were recorded to verify consistency of the control settings. Impact specimens were analyzed for the effect of temperature. Check socket specimens were also analyzed according to material type. Because definitive laminated sockets are composites that do not fail as complete breaks under impact, thus providing unreliable data, impact testing was not conducted on these materials.

One check socket (raw material) specimen from each supplier was initially impacted with a $5 \mathrm{ft}-\mathrm{lb}$ hammer. If the impact value was below $1.4 \mathrm{ft}-\mathrm{lb}$ (70\% of the next smallest hammer), the $2 \mathrm{ft}-\mathrm{lb}$ hammer was then used for the remaining specimens from that facility. Otherwise, testing continued with the $5 \mathrm{ft}-\mathrm{lb}$ hammer. A lighter hammer allowed for better resolution readings. Because the material specimens were very limited, this procedure was implemented to avoid the risk of wasting a specimen at the cost of occasional compromise in the sensitivity of the measure of the first specimen. For the copolymer sockets, the same procedure was used, except initial testing was conducted with a $30 \mathrm{ft}-\mathrm{lb}$ hammer. The type of break was classified into four categories: complete break, hinge break, partial break, and nonbreak. The break classifications are defined in Table 1. Because no classification is given in ASTM D-6110 [11], the verbal classification from ASTM D-256: Standard Test Method for Determining the Izod Pendulum Impact Resistance of Plastics [12] was utilized. According to ASTM D-6110, only the results from specimens classified as complete breaks will be reported [11].

Impact resistance was calculated by division of the net breaking energy by the measured width of the specimen. The net breaking energy was determined by subtraction of the frictional loss from the indicated breaking energy recorded directly off the test machine. Frictional loss of the dial indicator was determined by conduction of three consecutive swings for a given hammer with the specimen omitted. The dial indicator of the test machine was not reset between these swings but remained at the indicated breaking energy for the consecutive swings. The difference in the indicated breaking energy between the first and third swings was recorded as the frictional loss. Windage was considered to have been included in the design of the indicator dial. Frictional losses are due to the need for the test machine to drive the indicator dial and are therefore proportional to the distance the dial must be moved. The net breaking energy was calculated by subtraction of the frictional loss multiplied by the ratio of the indicated breaking energy to the maximum breaking energy for the given hammer from the indicated breaking energy. Frictional loss was calculated every 10 specimens or when a new hammer was used. This practice was implemented to account for any alterations in frictional loss due to the influence of extended usage, cold, and/or specific hammer utilization. 
JRRD, Volume 48, Number 8, 2011

Table 1.

Impact break classification as stated in American Society for Testing and Materials Standard D-256 [1].

Classification

Definition

Complete Break $\quad$ Break where specimen separates into two or more pieces.

Hinge Break

Incomplete break, such that one part of specimen cannot support itself above horizontal when other part is held vertically ( $<90^{\circ}$ included angle).

Partial Break

Incomplete break that does not meet definition for hinge break but has fractured at least $90 \%$ of distance between vertex of notch and opposite side.

Nonbreak

Incomplete break where fracture extends $<90 \%$ of distance between vertex of notch and opposite side.

1. ASTM Standard D-256, 2006a. Standard test method for determining the Izod pendulum impact resistance of plastics [Internet]. West Conshohocken (PA): ASTM International. Available from: http://www.astm.org/.

\section{Statistical Analysis}

Statistical analysis was conducted on the tensile and impact values according to the designed classifications with use of a one-way analysis of variance (ANOVA) with a 5 percent significance level. For analyses in which unequal variances were present, a Welch ANOVA was implemented. If a significant difference was identified, an additional comparison analysis was performed using the post hoc Tukey honestly significant difference means comparison at a 5 percent significance level. A commercially available software package was used to conduct all statistical analyses (JMP 8, SAS; Cary, North Carolina). Average and standard deviation values for the tensile and impact properties are also reported.

\section{RESULTS}

\section{Check Socket Material Tensile Properties}

Eight facilities provided check socket specimens for tensile analysis for a total of 48 socket tensile specimens. One facility provided sockets but removed and discarded the flat popliteal area before shipping, so no tensile specimens were available from that facility. For the three types of check socket material (PETG, Thermolyn Rigid, and Orfitrans Stiff), average and standard deviation values for tensile strength, modulus, and elongation are reported in Table 2. Statistical analysis of tensile strength $(p<0.001)$, modulus (Welch ANOVA: $p<0.001$ ), elongation at yield (Welch ANOVA: $p<0.001$ ), and elongation at break $(p<0.001)$ indicated a significant difference between the three types of check socket material. Thermolyn Rigid and Orfitrans Stiff material produced similar tensile properties. PETG material had higher tensile strength, higher modulus, and lower elongation at yield than Thermolyn Rigid or Orfitrans Stiff. Thermolyn Rigid materials had significantly higher elongations at break than other materials, while PETG and Orfitrans Stiff were not significantly different. According to ASTM Standard D-638, reported tensile strength is referenced by indicating the location of maximum stress, either at yield or at break [10]. PETG socket specimens had tensile strengths occurring at the yield point. In contrast, Thermolyn Rigid and Orfitrans Stiff had tensile strengths occurring at the break point. Thermolyn Rigid and Orfitrans Stiff socket specimens were exclusively fabricated by the blister-forming method. PETG socket specimens were constructed from both blister-forming and machine-pulled fabrication methods. No distinguishable differences were found between the two fabrication methods with regards to PETG tensile strength $(p=0.52)$, elongation at yield (Welch ANOVA: $p=0.14$ ), and elongation at break $(p=0.12)$. A significant difference in modulus was determined between the two fabrication methods $(p<0.001)$.

Seven facilities provided raw check socket material. Because the machine-pulled raw bell material is injection molded and also required flatting before machining, an additional nine specimens were collected to verify that orientation was not an influencing factor (minimum $p=$ 0.25 for all tensile properties was determined). One specimen was lost while data were being transferred from the test machine. Therefore, a total of 29 raw check socket specimens was analyzed.

The raw check socket material specimens produced similar trends as the fabricated socket specimens. All three types of material exhibited significantly different tensile strengths $(p<0.001)$, with PETG having the highest, 
Table 2.

Check socket material tensile strength, modulus, elongation at yield, and elongation at break (mean \pm standard deviation) for both fabricated sockets and raw materials. Polyethylene terephthalate glycol (PETG) material had tensile strengths at yield. Thermolyn Rigid and Orfitrans Stiff material had tensile strengths at break.

\begin{tabular}{lccccc}
\hline \multicolumn{1}{c}{ Material } & No. of Specimens & $\begin{array}{c}\text { Tensile Strength } \\
\text { (MPa) }\end{array}$ & $\begin{array}{c}\text { Modulus } \\
\text { (MPa) }\end{array}$ & $\begin{array}{c}\text { Elongation at } \\
\text { Yield (\%) }\end{array}$ & $\begin{array}{c}\text { Elongation at } \\
\text { Break (\%) }\end{array}$ \\
\hline Socket Sample & 36 & $53.7 \pm 1.9$ & $459 \pm 28$ & $24.1 \pm 3.1$ & $351 \pm 83$ \\
$\quad$ PETG & 6 & $15.5 \pm 1.2$ & $124 \pm 53$ & $79.9 \pm 12.0$ & $555 \pm 109$ \\
$\quad \begin{array}{l}\text { Thermolyn Rigid } \\
\text { Orfitrans Stiff }\end{array}$ & 6 & $15.2 \pm 0.5$ & $190 \pm 79$ & $68.4 \pm 8.0$ & $404 \pm 110$ \\
Raw Sample & & & & \\
$\quad$ PETG & 23 & $55.4 \pm 1.4$ & $405 \pm 38$ & $24.7 \pm 2.1$ & $429 \pm 71$ \\
$\quad$ Thermolyn Rigid & 3 & $24.4 \pm 0.6$ & $170 \pm 4.6$ & $70.3 \pm 2.6$ & $844 \pm 31$ \\
$\quad$ Orfitrans Stiff & 3 & $20.4 \pm 1.4$ & $266 \pm 41$ & $51.8 \pm 4.7$ & $622 \pm 117$ \\
\hline \hline
\end{tabular}

followed by Thermolyn Rigid and then Orfitrans Stiff. All three materials also exhibited significantly different values for their modulus $(p<0.001)$. PETG had the highest modulus, followed by Orfitrans Stiff and then Thermolyn Rigid with the lowest. All three types of materials exhibited significantly different elongation at yield ( $p<$ $0.001)$ and elongation at break $(p<0.001)$. For both analyses, Thermolyn Rigid had the highest elongation, followed by Orfitrans Stiff and then PETG. Tensile data for the raw check socket material specimens are located in Table 2.

When the socket specimen data were compared with the raw material data, the raw material tensile strength was significantly higher for all three types of material (PETG: $p<0.001$; Thermolyn Rigid: $p<0.001$; Orfitrans Stiff: $p<0.001)$. Modulus values from the raw material were significantly lower for the raw PETG material ( $p<$ 0.001 ) than for the socket specimens. Modulus values between raw material and socket material specimens were not significantly different for Thermolyn Rigid (Welch ANOVA: $p=0.09)$ and Orfitrans Stiff $(p=0.17)$. Elongation at yield was not significantly different for the PETG ( $p=0.46)$ and Thermolyn Rigid ( $p=0.21)$ materials; however, raw Orfitrans Stiff material had a significantly lower elongation at yield than the socket fabricated specimens $(p=0.01)$. Elongation at break from the raw material was significantly higher than the elongation at break produced from fabricated sockets for all three types of material (PETG: $p<0.001$; Thermolyn Rigid: $p=0.003$; Orfitrans Stiff: $p=0.03$ ). A sample of the stress-strain curves for the three types of material from both the raw material and socket fabricated material is located in Figure 3. These curves represent the response for each particular type of check socket material. Stress-strain

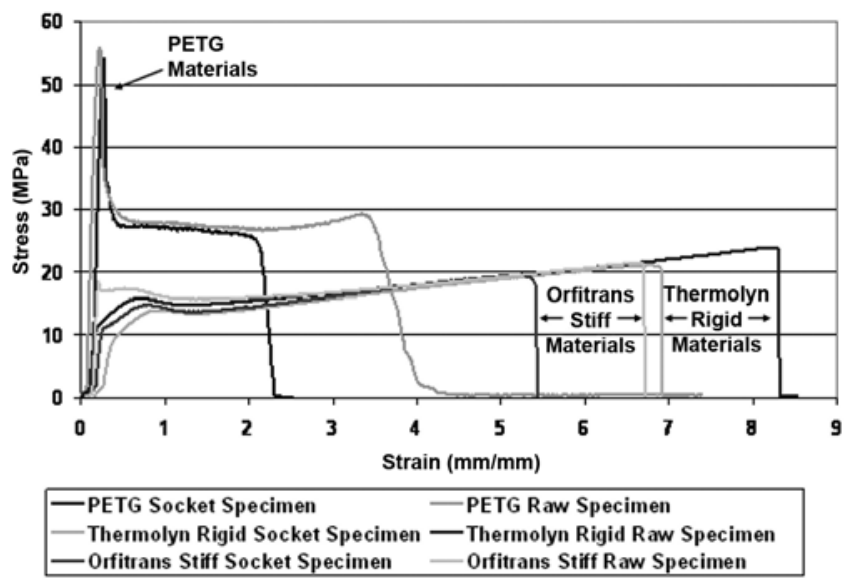

Figure 3.

Check socket material stress-strain curves for polyethylene terephthalate glycol (PETG), Thermolyn Rigid, and Orfitrans Stiff material produced by socket specimens and raw material specimens (example of one specimen each).

curves for Thermolyn Rigid and Orfitrans Stiff exhibited maxima at the break point, comparatively low stress at the yield point, and a relatively long strain elongation period before breaking. The stress-strain curves for the PETG material typically contained an initial high spike in stress followed by a precipitous drop to an extended plateau at a lower stress.

\section{Copolymer Socket Material Tensile Properties}

Table 3 contains tensile strength, modulus, elongation at yield, and elongation at break data for socket specimens and raw material specimens fabricated from copolymer socket material. These are sorted by socket fabrication method. Seven facilities provided sockets. However, all 
JRRD, Volume 48, Number 8, 2011

Table 3.

Copolymer socket material tensile strength at yield, modulus, elongation at yield, and elongation at break (mean \pm standard deviation) for both fabricated sockets and raw material.

\begin{tabular}{|c|c|c|c|c|c|}
\hline Method & No. of Specimens & $\begin{array}{l}\text { Tensile Strength } \\
\text { (MPa) }\end{array}$ & $\begin{array}{c}\text { Modulus } \\
\text { (MPa) }\end{array}$ & $\begin{array}{c}\text { Elongation at } \\
\text { Yield (\%) }\end{array}$ & $\begin{array}{c}\text { Elongation a } \\
\text { Break (\%) }\end{array}$ \\
\hline \multicolumn{6}{|l|}{ Socket Sample } \\
\hline Blister & 15 & $22.8 \pm 12.0$ & $253 \pm 34$ & $23.5 \pm 4.3$ & $349 \pm 322$ \\
\hline Drape & 12 & $22.9 \pm 1.9$ & $244 \pm 32$ & $24.4 \pm 2.9$ & $279 \pm 49$ \\
\hline Machine-Pulled & 12 & $24.2 \pm 5.4$ & $237 \pm 51$ & $27.3 \pm 4.0$ & $275 \pm 55$ \\
\hline Overall & 39 & $23.3 \pm 3.4$ & $245 \pm 39$ & $24.9 \pm 4.1$ & $305 \pm 202$ \\
\hline \multicolumn{6}{|l|}{ Raw Sample } \\
\hline Blister & 10 & $25.5 \pm 4.3$ & $284 \pm 30$ & $32.0 \pm 5.3$ & $678 \pm 307$ \\
\hline Drape & 3 & $23.8 \pm 0.4$ & $274 \pm 17$ & $26.5 \pm 3.4$ & $409 \pm 39$ \\
\hline Machine-Pulled & 4 & $26.9 \pm 0.8$ & $295 \pm 21$ & $34.3 \pm 5.7$ & $311 \pm 57$ \\
\hline Overall & 17 & $25.5 \pm 3.4$ & $285 \pm 26$ & $31.6 \pm 5.5$ & $544 \pm 286$ \\
\hline
\end{tabular}

the specimens from one of the facilities (total of six specimens) broke after the $300 \mathrm{~s}$ ASTM D-638 specification and only three specimens from another facility were used because of a warped popliteal area [10]. Therefore, a total of 39 specimens was tested. Differences in socket fabrication methods were not found to significantly affect the tensile strength (Welch ANOVA: $p=0.71$ ); modulus ( $p=$ 0.56 ), or elongation at break (Welch ANOVA: $p=0.05$ ). However, the choice of fabrication methods was found to result in a significant difference in copolymer socket material elongation at yield $(p=0.04)$. Means comparison testing determined a significant difference between the blister-formed and machine-pulled sockets, with blister-formed copolymer material having lower elongation at yield. A blister-to-drape comparison and a drape-tomachine-pulled comparison were not significantly different for elongation at yield. The overall averages for the copolymer socket material specimens are also located in Table 3.

A total of 17 specimens was analyzed. Six facilities provided raw copolymer material; however, four specimens slipped from the tensile grips and were omitted from analysis. Because the machine-pulled raw bell material required flatting, three additional specimens were machined to verify no influence of orientation (minimum $p=0.05$ for all tensile properties). In this study, no raw copolymer material used for a given fabrication method was found to be significantly different from the raw copolymer material used for any other fabrication method (tensile strength [ $p=0.52]$, modulus $[p=0.60]$, elongation at yield $[p=0.06]$, and elongation at break $[p=$
0.05]). The overall tensile data for the raw copolymer material specimens are also located in Table 3.

Because previous analysis demonstrated only a significant difference in elongation at yield for the copolymer socket specimens, an overall comparison between the raw and socket copolymer materials was conducted regardless of fabrication method. The tensile properties of copolymer specimens were affected by the fabrication methods. Fabrication resulted in significantly lower tensile strength $(p=0.02)$, modulus $(p<0.001)$, elongation at yield $(p<0.001)$, and elongation at break $(p<0.001)$ than did raw copolymer material. The mean difference between the fabricated and raw materials was $2.2 \mathrm{MPa}$ (8.6\%) for tensile strength, $40 \mathrm{MPa}(14 \%)$ for modulus, 6.7 percent for elongation at yield, and 239 percent for elongation at break. Figure 4 contains examples of the stress-strain curves from a raw copolymer material specimen and a drape-fabricated copolymer socket. The copolymer material stress-strain curves rapidly increased to a low yield point followed by a decay period of slow stress decline with a faster rate of strain incline. This indicates increased plastic behavior as opposed to brittle behavior. Several specimens had maxima occurring at the break point as opposed to the majority, which occurred at the yield point. The tensile strength, reported according to the location of the maximum, is summarized in Table 4.

Overall comparisons of thermoplastic material tensile strengths and elongation at break are located in Figures 5 and $\mathbf{6}$, respectively. 


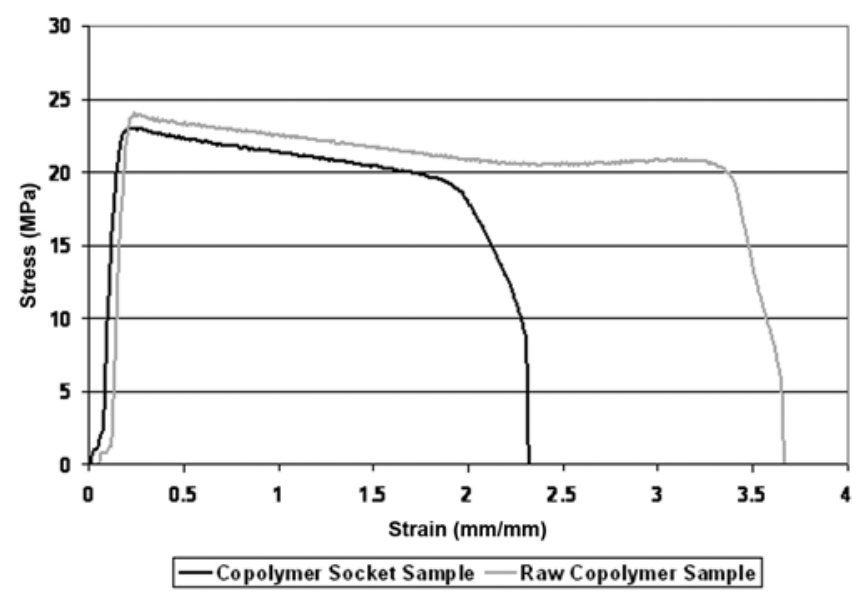

Figure 4.

Copolymer material stress-strain curves produced by socket specimen and raw material specimen (one specimen each).

\section{Definitive Laminated Socket Material Tensile Properties}

A total of 49 specimens was analyzed. All nine facilities provided definitive laminated sockets. However, only three specimens were obtained from one facility because the popliteal area was warped. Also, data from two other specimens were lost while the data were being transferred from the test machine. The definitive laminated socket material tensile properties were classified into three material fabrication techniques: carbon lamination with nonpigmented resin, carbon lamination with pigmented resin, and nyglass.

Raw material analysis was not performed on the laminated sockets because of the composite structure. The mechanical properties of composite materials are highly dependent on fiber orientation, fiber type, matrix type, lamination process, and many other factors that were not known in this study. Specifically, information regarding resin and construction lay-up was not available and orientation could not be controlled in the test samples. These factors significantly limited the scope of this study for the laminated samples. Isolated coupon specimens of the composite laminated sockets provide only a portion of the material property information. Additional knowledge can be gained by testing of the composite material in the intended application form, i.e., a prosthetic socket. Evaluation of the complete prosthetic socket structure was performed using the sockets delivered for this study and the results will be forthcoming in a separate study.

In ASTM Standard D-638, tensile strength is designated by noting whether the maximum stress occurred at yield or at break [10]. Roughly half the specimens had maxima occurring at the yield point while the other half occurred at the break point. Because measured tensile strength $(p=0.02)$ and modulus $(p=0.005)$ significantly differed between the two types of failure presentations, further statistical analysis was separated according to the presentation (failure at yield or break) of tensile strength. Tensile data for each combination (fabrication technique and tensile strength failure presentation) are located in Table 5.

For the specimens having maxima at the yield point, no resulting significant difference in tensile strength $(p=$ 0.69 ) or modulus (Welch ANOVA: $p=0.16$ ) was identified between fabrication techniques. However, a significant difference was found in measured elongation at yield ( $p=0.15)$, with nyglass producing a statistically higher elongation than the other two fabrication techniques. No significant difference in elongation was found

Table 4.

Copolymer material tensile properties (mean \pm standard deviation) reported by tensile strength designation.

\begin{tabular}{|c|c|c|c|c|c|}
\hline $\begin{array}{l}\text { Tensile Strength } \\
\text { Designation }\end{array}$ & No. of Specimens & $\begin{array}{c}\text { Tensile Strength } \\
\text { (MPa) }\end{array}$ & $\begin{array}{l}\text { Modulus } \\
\text { (MPa) }\end{array}$ & $\begin{array}{l}\text { Elongation at } \\
\text { Yield (\%) }\end{array}$ & $\begin{array}{c}\text { Elongation at } \\
\text { Break (\%) }\end{array}$ \\
\hline \multicolumn{6}{|l|}{ Socket Sample } \\
\hline $\begin{array}{l}\text { Tensile Strength } \\
\text { at Yield }\end{array}$ & 31 & $24.4 \pm 2.4$ & $238 \pm 37$ & $25.7 \pm 3.9$ & $279 \pm 117$ \\
\hline $\begin{array}{l}\text { Tensile Strength } \\
\text { at Break }\end{array}$ & 8 & $26.6 \pm 4.5$ & $273 \pm 39$ & $22.0 \pm 3.5$ & $404 \pm 387$ \\
\hline \multicolumn{6}{|l|}{ Raw Sample } \\
\hline $\begin{array}{l}\text { Tensile Strength at } \\
\text { Yield }\end{array}$ & 15 & $25.0 \pm 2.0$ & $279 \pm 17$ & $31.1 \pm 4.5$ & $481 \pm 192$ \\
\hline $\begin{array}{l}\text { Tensile Strength at } \\
\text { Break }\end{array}$ & 2 & $29.5 \pm 9.7$ & $332 \pm 39$ & $35.5 \pm 12.8$ & $1,013 \pm 544$ \\
\hline
\end{tabular}




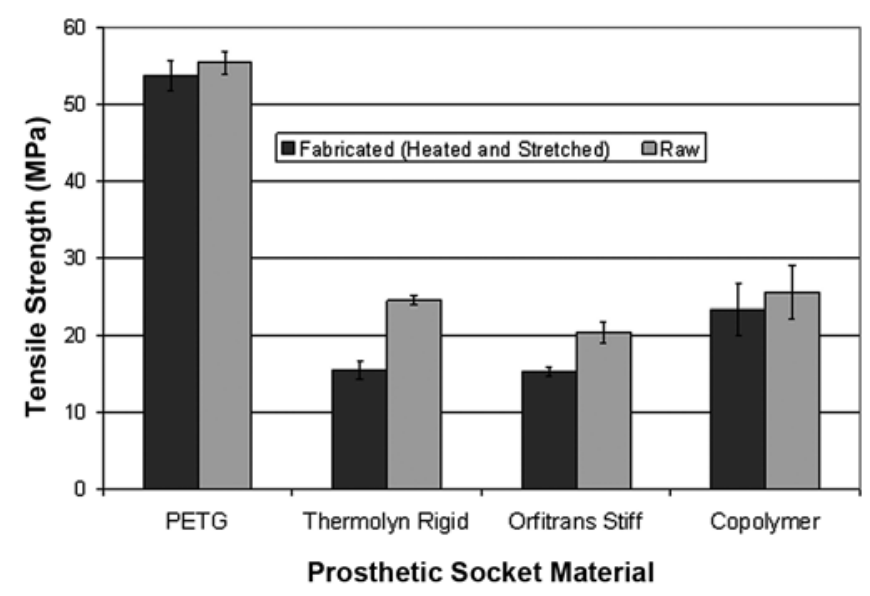

Figure 5.

Thermoplastic tensile strength comparison including results from both fabricated (heated and stretched) specimens and raw material specimens. Raw specimens and fabricated specimens significantly differed for all four types of material. PETG = polyethylene terephthalate gylcol.

between carbon lamination with nonpigmented resin and carbon lamination with pigmented resin. In contrast, specimens having maxima at the break point indicated a significant difference in tensile strength $(p=0.01)$ and modulus $(p=0.01)$ between material choices. Carbon lamination with pigmented resin had higher tensile strength values and modulus values than carbon laminate with nonpigmented specimens. This is displayed on the stress-strain curve (Figure 7) with the carbon laminate with pigmented resin specimen producing a higher stress value. A possible explanation is that the added particulates in a pigmented resin can conceivably stiffen the material. No significant difference $(p=0.34)$ in elongation was measured between the material categories. None of the nyglass specimens had maxima at the break point. Figure 7 contains stress-strain curves for all fabrication techniques for both types of tensile strength. The stairstep appearance of the data is the result of the need to maintain full travel and load ranges for laminated specimens so as to not lose data for a particularly stiff or extensible specimen. This resulted in less than ideal resolution and a stairstep effect to some of the data.

\section{Check Socket Raw Material Impact Properties}

Check socket raw material impact tests were conducted at two different temperature control settings: freezer $\left(-8.7^{\circ} \mathrm{C} \pm 1.2^{\circ} \mathrm{C}\right)$ and room temperature $\left(25.5^{\circ} \mathrm{C} \pm\right.$ $\left.0.1^{\circ} \mathrm{C}\right)$. A total of 44 specimens split evenly between

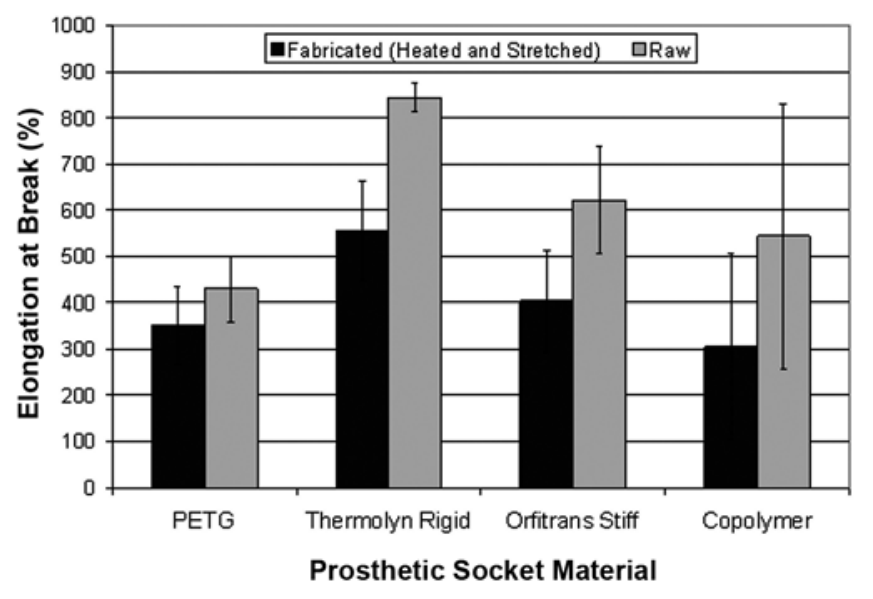

Figure 6.

Thermoplastic elongation at break comparison including results from both fabricated (heated and stretched) specimens and raw material specimens. Raw specimens and fabricated specimens significantly differed for all four types of material. PETG = polyethylene terephthalate glycol.

these two temperatures was used in the analysis. Seven facilities provided flat check socket raw material, and six specimens were CNC machined from each sheet. One facility's machine-pulled raw material was bell-shaped, which required heating and flattening before machining the specimens. Four additional specimens were collected from the bell-shaped material to determine whether orientation was an influence. Two specimens were omitted because of test machine malfunction. The results were analyzed for the three different types of check socket raw materials (PETG, Thermolyn Rigid, and Orfitrans Stiff) at each temperature setting. Impact data are summarized in Table 6.

The Orfitrans Stiff raw material for the freezer condition $\left(-8.7^{\circ} \mathrm{C}\right)$ consisted of one specimen because the machine malfunctioned while testing the other two specimens. The remaining valid data point is reflected in Table 6. However, statistical analysis was only performed on the data collected from PETG and Thermolyn Rigid material specimens at the lower temperature. For PETG materials, impact resistance was found to be significantly influenced by temperature, with lower temperatures leading to lower impact resistance. (Welch ANOVA: $p<0.001$ ). No significant difference in impact resistance was detected for the Thermolyn Rigid specimens $(p=0.67)$. The evaluation of material type revealed that Thermolyn Rigid material produced significantly lower impact resistance than PETG material at both temperature control settings $(p<0.001$ for both temperature 
Table 5.

Definitive laminated socket material tensile strength, modulus, and elongation at yield/break (mean \pm standard deviation) grouped by tensile strength designation and fabrication technique.

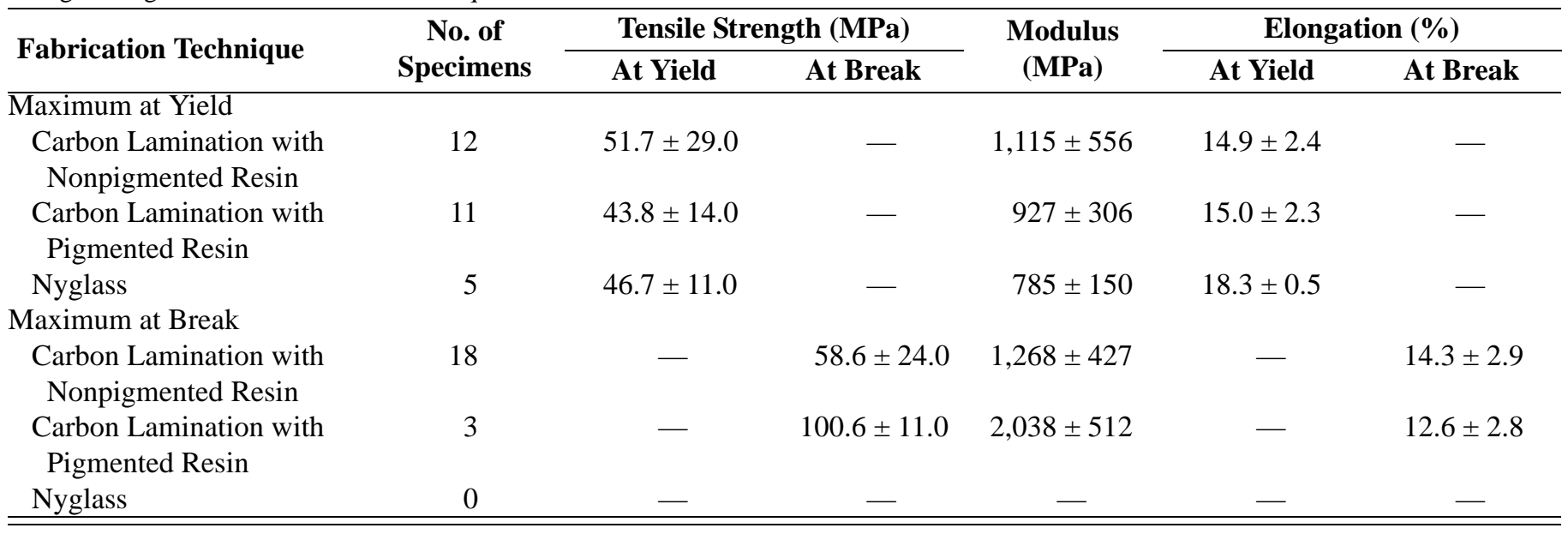

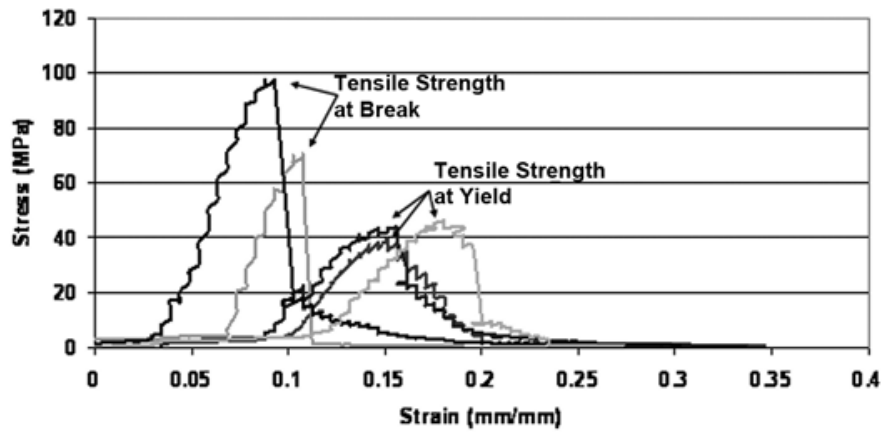

- Carbon Lamination with Non-Pigmented Resin - Tensile Strength at Yield - Carbon Lamination with Non-Pigmented Resin - Tensile Strength at Break - Carbon Lamination with Pigmented Resin - Tensile Strength at Yield - Carbon Lamination with Pigmented Resin - Tensile Strength at Break - Nyglass - Tensile Strength at Yield

Figure 7.

Sample of definitive laminated socket material stress-strain curves generated from carbon lamination with nonpigmented resin, carbon lamination with pigmented resin, and Nyglass (one sample specimen of each). Tensile strength designation is indicated.

control settings). Orfitrans Stiff at room temperature $\left(25.5^{\circ} \mathrm{C}\right)$ had significantly lower impact resistance than PETG but was not significantly different from Thermolyn Rigid. Assessments of machine-pulled, bell-shaped, PETG specimens indicated no influence of orientation (at $-8.7^{\circ} \mathrm{C}$ : $p=0.80$; at $25.5^{\circ} \mathrm{C}: p=0.25$ ).

\section{Copolymer Raw Material Impact Properties}

The copolymer raw material impact tests were also conducted under two specified temperature control settings: freezer $\left(-8.7^{\circ} \mathrm{C} \pm 1.2^{\circ} \mathrm{C}\right)$ and room temperature $\left(25.5^{\circ} \mathrm{C} \pm 0.1^{\circ} \mathrm{C}\right)$. A total of 39 specimens was analyzed, split between the freezer (19 specimens) and room temperature (20 specimens) control settings. A total of six facilities provided raw copolymer material. The machinepulled raw material from one facility was bell-shaped and was therefore heated and flattened before machining specimens. Three additional specimens were obtained from the bell-shaped raw material to determine whether orientation was an influencing factor. The impact resistance analysis for the raw copolymer material excluded the room temperature $\left(25.5^{\circ} \mathrm{C}\right)$ specimens because they were not classified as complete breaks. These specimens were classified as hinge breaks or partial breaks, and the plastic nature of these types of breaks resulted in higher impact resistance values. The impact resistance for the freezer $\left(-8.7^{\circ} \mathrm{C}\right)$ copolymer material specimens is summarized in Table 6. Orientation did not appear to influence the machine-pulled, bell-shaped, freezer impact specimens $(p=0.63)$. An overall comparison of thermoplastic impact resistances is located in Figure 8.

\section{DISCUSSION}

\section{Study Limitations}

Because this study evaluated samples of prosthetic socket materials supplied by various sources of prosthetic sockets, there were some limitations. Specimen thickness was not constant between samples and impact energies were scaled to the measured thickness. A more rigorous study could be constructed to evaluate base material 
JRRD, Volume 48, Number 8, 2011

Table 6.

Average (mean \pm standard deviation) impact resistance for check socket and copolymer materials.

\begin{tabular}{|c|c|c|c|c|}
\hline Material & $\begin{array}{l}\text { No. of Specimens } \\
\text { at }-8.7^{\circ} \mathrm{C}\end{array}$ & $\begin{array}{c}\text { Impact Resistance } \\
\text { at }-8.7^{\circ} \mathrm{C}(\mathrm{J} / \mathrm{m})\end{array}$ & $\begin{array}{c}\text { No. of Specimens } \\
\text { at } 25.5^{\circ} \mathrm{C}\end{array}$ & $\begin{array}{c}\text { Impact Resistance } \\
\text { at } 25.5^{\circ} \mathrm{C}(\mathrm{J} / \mathrm{m})\end{array}$ \\
\hline \multicolumn{5}{|l|}{ Check Socket } \\
\hline PETG & 18 & $84.9 \pm 9.3$ & 16 & $114 \pm 25$ \\
\hline Orfitrans Stiff & 1 & 50 & 3 & $42.2 \pm 0.42$ \\
\hline Copolymer Socket & 19 & $211 \pm 72$ & - & - \\
\hline
\end{tabular}

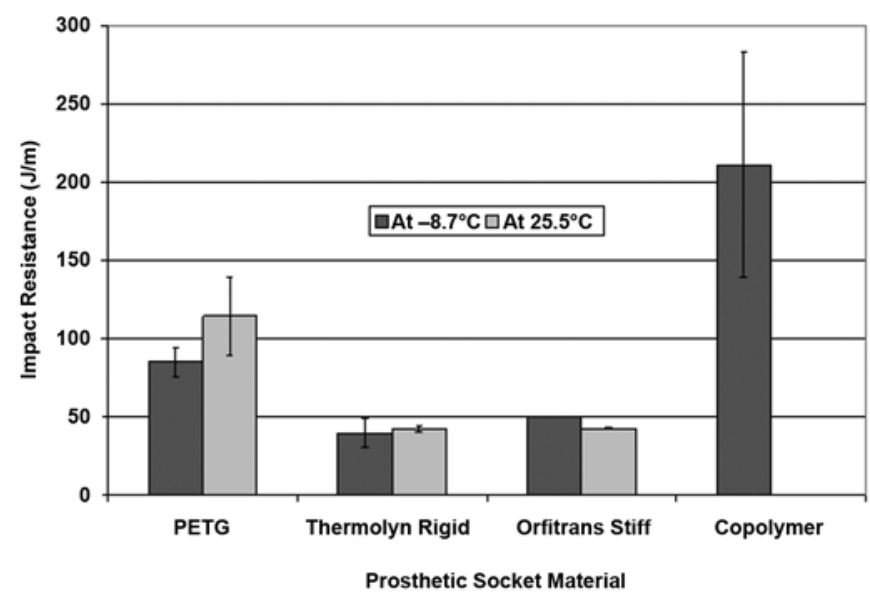

Figure 8.

Thermoplastic impact resistance comparison conducted at cold $\left(-8.7^{\circ} \mathrm{C}\right)$ and room $\left(25.5^{\circ} \mathrm{C}\right)$ temperatures. Copolymer's impact resistance at $25.5^{\circ} \mathrm{C}$ was not reported because of incomplete breaks, suggesting influence of temperature. For check socket materials, polyethylene terephthalate glycol (PETG) was only material found to be significantly affected by temperature.

properties by ordering thicker samples from materials vendors. However, this would not necessarily be more indicative of the materials as supplied to and used in the field.

This study was also hampered by a very limited number of samples. Based on this consideration, the loss of any specimen was considered costly to the experiment. For this reason, compromises in data resolution were made in several instances to ensure that load, travel, or impact energy ranges were never exceeded. While this did result in some step effects in the graphs of loads and strains, this effect is not believed to have affected the overall results.

Variability between specimens was potentially higher because the tensile socket specimens were extracted from the flat posterior popliteal area of the socket, which is normally discarded. This was most apparent in the carbon tensile specimens with the presence of uneven thickness distribution between specimens. Minimal information regarding lamination materials and process parameters for all materials limited the study analysis. In addition to this and because the loading rates for the tensile test were different for the lamination materials compared with both the check socket materials and copolymer materials, comparisons were unable to be drawn between all types of sockets. However, comparisons were drawn between the check socket and copolymer materials.

Other studies have concluded that material aging has a large effect on yield strength and other material behaviors [13-15]. Because materials were supplied by different facilities using different vendors, the study was unable to assess or minimize the effects of aged material. Also, the thickness of a sample can have other effects. While beyond the scope of this current study, an ad hoc evaluation of the effects of sample thickness on impact energy indicated that some materials exhibit a transition from brittle to ductile behavior as the sample thickness decreases. This effect is probably worth further evaluation and may further complicate the effects of pulling materials over a prosthetic model.

For the impact test, a heavier hammer was used initially on one specimen from each supplier and results were evaluated to determine whether to continue testing with the heavier hammer. Because the initial tests indicated that the results were within the range of a lighter hammer, the lighter hammer was then used for subsequent tests to provide better resolution. Ideally, calibration specimens from each supplier would be implemented; however, the lack of materials prevented this option. As a result, some precision was lost for the initial specimen of some of the materials.

Definitive laminated socket tensile strengths were measured either at the yield point or the break point, 
depending on the material's behavior. Unfortunately, while some significant differences could be measured between the sample types, these properties are probably not representative of these materials' performances in structures because specimens cut from fabricated sockets do not exhibit the types of control over material selection, orientation, and fabrication technique necessary to rigorously evaluate material properties with limited sample sizes. Further work that overcomes these limitations by testing complete sockets is in process.

\section{Thermoplastic Polymer Behavior}

The check socket and copolymer materials had characteristically different stress-strain curves, indicating that the materials exhibit different macroscopic mechanical behaviors. Polymeric materials experience two types of postyielding characteristics: strain softening and strain hardening [13]. Strain softening, an intrinsic behavior, tends to lead to unstable localized strains after yielding. The localized strains destabilize the macroscopic properties of the material, resulting in early propagation of cracks, thus increasing the brittleness of the material [13]. In glassy polymer materials, strain softening is followed by the stabilization of the material, referred to as strain hardening. During strain hardening, the orientation of the polymer molecules forces the stress to distribute over a greater surface area. The material's toughness is increased as the deformation energy then dissipates over the larger area [13-14]. Depending on which factor dominates postyield in a given loading scenario, the material exhibits a resulting brittle or ductile response.

Increased material toughness is beneficial for socket performance. Smit et al. introduced the concepts of either reducing the strain softening or increasing the strain hardening to improve toughness [13]. However, Smit et al. also mentioned that techniques for reducing strain softening also tended to reduce yield strength, which is undesirable [13]. The PETG material, with high yield strength, exhibited strain softening with the drastic decrease in stress following yielding. This increased the brittleness of the material, and the strain hardening behavior was cut short before it could compensate for the loss in modulus. In contrast, Thermolyn Rigid, Orfitrans Stiff, and copolymer materials displayed less intrinsic strain softening than PETG material. These materials also had a more pronounced strain hardening with the stress increasing as strain grew postyielding. Thermolyn Rigid had the highest percent strain, followed by Orfitrans Stiff.
The material stress-strain curves are presented in Figures 3 and 4.

The energy necessary to rupture a material, or "essential work," is a measurement of the material's toughness. Energy absorbed by specimens from fabricated thermoplastic polymer materials was compared with the energy absorbed by the raw thermoplastic polymer materials. The specimens used in this study do not comply with those optimized for the study of essential work, and as such, the values obtained from this study should not be expected to compare with those in other materials studies. However, the relative measures obtained with these samples can give a comparative analysis of the materials as used in prosthetics. The analysis included six facilities for both the check socket material and the copolymer material. The other three facilities were omitted as a result of unsupplied material, either raw material specimens or socket specimens. Each facility was individually analyzed because of possible variation in fabrication technique. The percent of a raw material's essential energy absorbed during the fabrication process is reported in Table 7. The average energy from each facility normalized by thickness was used in the percentage calculation. For the check socket material, slightly more energy was absorbed during the blister-forming fabrication of the Thermolyn Rigid and Orfitrans Stiff materials compared with the PETG material. The percentage of energy absorbed for the copolymer materials varied considerably between facilities, suggesting that fabrication techniques of a specific individual may have a stronger influence than the fabrication method. Also, two occurrences of negative percentages occurred, indicating an increase in the ability to absorb energy in deformation. A possible explanation is that the "raw material" in fact had significant residual stresses as received and that the process of heating the material for fabrication effectively annealed the raw material and thus released more residual stress than was created during the fabrication process. This effect was demonstrated by testing of additional PETG raw material specimens from Facility 3. The tensile load-displacement curve for the raw specimens, heated specimens (no manual work), and the heated/ pulled-flat specimens (Figure 9) displayed the effect of annealing. The heated specimens did not experience significantly reduced yield strength; however, they did exhibit increased elongation before breaking, indicating annealing effects. The heated and pulled specimens displayed a slightly longer elongation than the heated specimens. The 
JRRD, Volume 48, Number 8, 2011

Table 7.

Available essential work consumed by fabrication methods for check and copolymer sockets.

\begin{tabular}{|c|c|c|c|c|c|c|}
\hline \multirow{2}{*}{ Facility } & \multicolumn{2}{|c|}{ \% Used in Fabrication* } & \multicolumn{2}{|c|}{ Material } & \multicolumn{2}{|c|}{ Fabrication Method } \\
\hline & Check & Copolymer & Check & Copolymer & Check & Copolymer \\
\hline 1 & 44 & -80 & Orfitrans Stiff & Copolymer & Blister & Blister \\
\hline 2 & 32 & 36 & PETG & Copolymer & Blister & Drape \\
\hline 3 & -60 & 21 & PETG & Copolymer & Blister & Blister \\
\hline 4 & 30 & 74 & PETG & Copolymer & Blister & Blister \\
\hline 5 & 36 & 18 & PETG & Copolymer & Machine-Pulled & Machine-Pulled \\
\hline 6 & 43 & - & Thermolyn Rigid & - & Blister & - \\
\hline 7 & - & 88 & - & Copolymer & - & Blister \\
\hline
\end{tabular}

${ }^{*}$ Energies normalized by thickness before calculation of percentages. PETG = polyethylene terephthalate glycol.

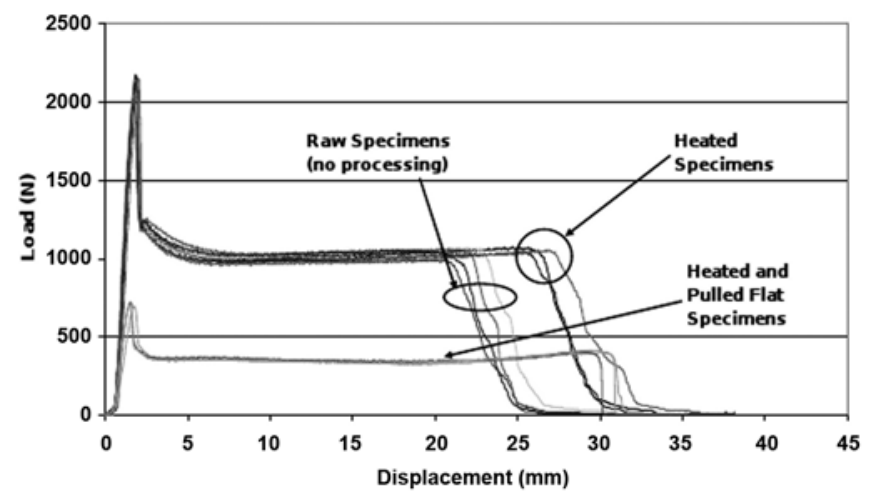

Figure 9.

Annealing analysis using polyethylene terephthalate glycol material.

heated and pulled specimens were thinner than the unpulled specimens; therefore, the load drop does not indicate a drop in stress. When normalized by specimen thickness, the energy necessary to create a rupture for this specimen was greater than the raw material and slightly greater than the heated specimen. The heated and heated/ pulled specimens were allowed to cool in ambient air rather than quenching. In addition to these factors, a study conducted by Klompen illustrated that quenching a material can lead to embrittlement [14], presumably by the introduction of residual stresses like those demonstrated in the raw material from Facility 3 . This evaluation indicates that a material's essential work of fracture, in essence its toughness, may be affected during the fabrication process by the amount of annealing, the amount of manual work, the temperature at which this work occurs, the cooling process, and the manufacturing processes used to create the raw material. In a manual pro- cess where the material is experiencing differential cooling through varying thicknesses as the technician is stretching the material over a randomly shaped object, the industry's development of methods to produce functional sockets is impressive and a testament to the dedication of these professionals. Even so, these effects were noted in the materials pulled from prosthetic sockets and affected the performance of these sockets in ways that probably could not have been predicted. An analysis of these sockets is forthcoming in another study.

\section{Comparison Between Thermoplastic Polymers}

Testing of check socket materials indicates that Thermolyn Rigid and Orfitrans Stiff materials have lower tensile strength and impact resistance than PETG materials and would be expected to be much more susceptible to static and impact failures if used in similar manners. These differences in check socket material properties indicate that these materials are not interchangeable and should probably be used in different ways. Further, Thermolyn Rigid and Orfitrans Stiff materials have similar tensile and impact properties and appear to be more sensitive to manufacturing practices than PETG materials (Figures 5, 6, and 8).

Tensile properties for copolymer materials had similar tensile strength to Thermolyn Rigid and Orfitrans Stiff check socket materials (Figure 5). However, a notable difference between the tested classes of thermoplastic materials was the superior impact resistance of the copolymer materials. In particular, the impact resistance of the copolymer materials at low temperature was significantly different from the other materials, exhibiting 5.0 times more impact resistance than Thermolyn Rigid, 4.0 times more impact resistance than Orfitrans Stiff, and 2.5 times 
more impact resistance than PETG (Figure 8). Direct comparison of impact resistance at room temperature could not be performed because the copolymer material specimens simply could not be reliably fractured using a standard impact test. However, the materials exhibiting ductile failures absorbed more energy than the materials with brittle failures. This at least indirectly indicates that the copolymer materials perform better in impact situations at room temperature as well. As such, the data indicate that copolymer materials generally have a greater resistance to breakage caused by impact forces. However, when compared with PETG material, this impact resistance comes at the cost of a reduced tensile strength and hence a reduced ability to resist the static forces that can cause a socket to buckle or bend during ambulation. Amputees' sockets constructed from copolymer material at room temperature or lower temperatures are more resistant to impact forces typically encountered by falls than are the check socket materials. In contrast, PETG material is more resistant to tensile forces typically encountered by static forces during ambulation than copolymer materials, Thermolyn Rigid, and Orfitrans Stiff. However, elongation at break, indicative of the amount of allowable deformation, was greater for Thermolyn Rigid and Orfitrans Stiff than PETG and copolymer materials, signifying a more desirable ductile response. These differences in material performance may indicate that the use of some materials are more appropriate for colder climates or more active patients and shed some light on the reasons that copolymer materials are sometimes considered more appropriate for use in definitive sockets even though their tensile strength and elongation at break were comparable to or lower than those of other thermoplastic materials evaluated in this study.

For both check and copolymer socket specimens, the fabrication processes of heating and stretching typically altered tensile properties by reducing tensile strength and elongation at break, sometimes dramatically (Figures 5 and 6). There was also some indication that the methods used to manufacture the check socket materials, before delivery to the fabricator, can result in unpredictable residual stresses in the materials, which can, in turn, affect the quality of the final prosthesis. Raw copolymer material gathered from the various facilities had relatively consistent tensile properties; therefore, differences in fabricated copolymer socket tensile properties can be attributed to the fabrication process. These facts point out the important role that material choice, material history, and fabrication techniques play in the quality of the final prosthesis, and the significance of the fact that there is little awareness of, and few controls over, these factors in the industry.

The machine-pulled PETG and copolymer raw materials were received in a preformed bell-shape instead of a flat sheet. Therefore, the material required heating and flattening before testing. This processing appeared to slightly anneal the specimens; however, no significant difference was determined between these postflatten specimens and the corresponding materials received in flat sheets.

Check socket material product specification sheets available from manufacturers' Web sites indicated slightly different raw material tensile strength values than the values reported in this research. The PETG product sheet listed tensile strength at $53 \mathrm{MPa}$ [16] compared with $55.4 \mathrm{MPa}( \pm 1.4 \mathrm{MPa})$ measured in this study. For the Orfitrans Stiff material, the product sheet stated a tensile strength of $26 \mathrm{MPa}$ [17] versus $20.4 \mathrm{MPa}( \pm 1.4 \mathrm{MPa})$ measured in this study. A product sheet for the Thermolyn Rigid material was not available but according to a manufacturer representative the tensile strength is 26.0 $\mathrm{MPa}^{*}$ compared with $24.4 \mathrm{MPa}( \pm 0.56 \mathrm{MPa})$ measured in this study. Several factors contributing to the difference include no specified tolerance level on the product information sheets, temperature and humidity levels during testing, possible usage of a different measuring standard, specimen preparation, and dimensional differences. For the copolymer material, the product information sheet from one manufacturer listed a tensile strength value (23 MPa; www.northseaplastics.com) that was comparable to the raw material tensile strength measured in this study $(25.5 \pm 3.4 \mathrm{MPa})$.

\section{Definitive Laminated Socket Material Tensile Properties}

Definitive laminated sockets are composite structures whose properties are directly related to fiber selection and lay-up, matrix (resin) material selection, and individual fabrication practices, many of which were unknown and beyond the scope of this study. For this reason, only fabricated specimens were analyzed for the laminated sockets. The tensile properties were analyzed according

\footnotetext{
*Gerschutz, Maria (The Ohio Willow Wood Company, Mt. Sterling, $\mathrm{OH}$ ). Conversation with: Sales representative (Otto Bock Healthcare; Minneapolis, Minnesota). 2010 Jul 1.
} 
to the location of maximum load, tensile strength at yield, or tensile strength at break. Average elongation values were reported only for the corresponding location of tensile strength. Information regarding resin and construction lay-up was not provided; therefore, tensile properties were categorized first by material type and then second by the presence or absence of pigment in the resin. The categorization included carbon lamination with nonpigmented resin, carbon lamination with pigmented resin, and nyglass.

The difference between tensile strength at yield and tensile strength at break may be influenced by the amount and type of resin used in the specimen. Additional factors that may influence tensile properties include the use of a stocking, carbon fiber toe width, fiber selection, and orientation. According to Phillips and Craelius, fiber angle orientation containing only $\pm 45^{\circ}$ layers would contain a direction orientation with one axial direction weaker than another [5]. Taylor et al. analyzed the influence of orientation in carbon fiber laminates [4]. The study displayed an orientation of $0^{\circ} / 90^{\circ}$ and resulted in a tensile strength between 433 to $588 \mathrm{MPa}$, which was significantly more than the $\pm 45^{\circ}$ orientation with tensile strength between 12.2 to 76.8 MPa [4]. Phillips and Craelius classified carbon with a tensile strength value between 236 to $249 \mathrm{MPa}$ at a $0^{\circ} / 90^{\circ}$ orientation [5]. Both studies used the same standard and resin. The variability in these results signifies the influence of fabrication technique. Compared with the presented research, both carbon fiber laminate categories performed worse than both $0^{\circ} / 90^{\circ}$ orientation carbon fiber values determined in the study by Taylor et al. [4] and the carbon values in the study by Phillips and Craelius [5]. The tensile values for carbon fiber laminates (carbon lamination with nonpigmented resin: 58.6 MPa; carbon lamination with pigmented resin: 100.6 MPa) were similar to the $\pm 45^{\circ}$ orientation tensile strength values presented by Taylor et al. [4]. Information regarding construction lay-up and resin material was not provided by all suppliers and was therefore not available or analyzed. Because of the lower tensile strength values and visual examination of the samples, there is a strong potential that most carbon fiber sockets were constructed from a $\pm 45^{\circ}$ oriented fiber weave and that the tensile test was therefore more indicative of the matrix strength.

While ASTM Standard D-638 is a tensile standard for plastics, it was used on the definitive laminates to maintain a uniform measurement technique across materials. The form and quantity of available socket material restricted the size and number of specimens available for evaluation. For this reason, specimens with shorter gauge lengths were used and this resulted in a less than ideal resolution in strain. This reduced resolution resulted in some stairstep effects in some of the data (Figure 7). Definitive laminated data were collected with a $0.5 \mathrm{~mm}$ resolution and a $1.5 \mathrm{~mm}$ bit quantification error. A previous study used ASTM Standard D-3039 and a considerably larger gauge length (127 vs $7.62 \mathrm{~mm})$ and width (25.4 vs $3.18 \mathrm{~mm}$ ) [5]. Because of the size and shape of the specimens in both standards, the tensile strength may be more indicative of the rupture of the matrix (resin) and/or the separation of fiber and matrix (resin) bond rather than the true strength of the structure fabricated with the reinforcement material and matrix. A supplemental approach to this evaluation is to test the overall structure, i.e., socket, and compare this to other sockets manufactured with other materials. The sockets from which the material specimens were removed have undergone such a testing regimen and the results will be presented in a separate study.

\section{CONCLUSIONS}

The intent of this study was to evaluate the mechanical properties of commonly used, state-of-the-art prosthetic socket materials. Specifically, testing of tensile and impact properties was performed on both raw and fabricated materials obtained from central fabrication centers and clinical practices. In general, the mechanical properties of the material in a given conventional check or definitive socket were shown to depend on numerous factors, including the materials used, form of raw material, the chosen fabrication practices, and the temperature at which the prosthesis is used. This collection of factors, many of which depend on the evaluations and practices of the practitioner and some of which are beyond the knowledge of the practitioner, could be expected to be difficult to control in general practice. As such, these factors could result in a significant variation in performance of the resulting sockets. A tribute is given to the practice of prosthetics because most sockets fabricated with the current state of the art do function well. However, this performance is achieved through unwritten, handeddown rules of thumb. While most of these are in fact helpful, some are likely to be detrimental to at least some processes if the underlying materials considerations are not comprehended. An understanding of these factors and 
how they affect the final product may aid with the selection of materials and fabrication practices and result in improved performance of the prosthetic sockets delivered to future patients. This knowledge will also allow for the development of improved materials or methods and ultimately improved patient care. To this end, an evaluation of the sockets resulting from this mixture of factors is now in process.

\section{ACKNOWLEDGMENTS}

\section{Author Contributions:}

Study concept and design: M. L. Haynes, M. J. Gerschutz, D. M. Nixon, J. M. Colvin.

Acquisition of data: D. M. Nixon.

Analysis and interpretation of data: M. J. Gerschutz, M. L. Haynes.

Drafting of manuscript: M. J. Gerschutz, M. L. Haynes.

Critical revision of manuscript for important intellectual content:

M. J. Gerschutz, M. L. Haynes, J. M. Colvin.

Statistical analysis: M. J. Gerschutz.

Financial Disclosures: All authors are employed by The Ohio Willow Wood Company, which has an internal Central Fabrication Facility. Even though none of the authors works in the facility and the facility's materials were not evaluated in the submitted manuscript, knowledge gained from the submitted manuscript will help improve the product quality of the facility and potentially other central fabrication facilities. The Ohio Willow Wood Company's Central Fabrication Facility labeled the material upon arrival and trimmed a section of material from the fabricated sockets so samples could be machined and prepped for testing. The Central Fabrication Facility did not machine or prep the samples.

Funding/Support: This material was based on a research and development project conducted by The Ohio Willow Wood Company supported by a contract grant awarded and administered by the U.S. Army Medical Research and Materiel Command and the Telemedicine and Advanced Technology Research Center (contract W81XWH-08-10700). Additional Contributions: The authors wish to acknowledge Phillip Simmers and Steve Duemmel for their assistance in preparing and testing specimens.

\section{REFERENCES}

1. Klute GK, Rowe GI, Mamishev AV, Ledoux WR. The thermal conductivity of prosthetic sockets and liners. Prosthet Orthot Int. 2007;31(3):292-99. [PMID: 17979015] DOI:10.1080/03093640601042554

2. Sanders JE, Rogers EL, Sorenson EA, Lee GS, Abrahamson DC. CAD/CAM transtibial prosthetic sockets from central fabrication facilities: How accurate are they? J Rehabil Res Dev. 2007;44(3):395-405. [PMID: 18247236]

DOI:10.1682/JRRD.2006.06.0069
3. Taylor D. Lower-limb prosthetics-Mechanical testing prosthetic sockets. 2005 Journal of Proceedings; 2005 Mar 16-19; Orlando, FL; Journal of Proceedings. Washington (DC): American Academy of Orthotists \& Prosthetists; 2005. p. 34-37.

4. Taylor DA, Gilbert JC, Lautenschlager EP. Testing of composite materials used in orthotics and prosthetics. J Assoc Child Prosthet Orthot Clin. 1992;27(2):62.

5. Phillips SL, Craelius W. Material properties of selected prosthetic laminates. J Prosthet Orthot. 2005;17(1):27-33. DOI:10.1097/00008526-200501000-00007

6. Klasson BL. Carbon fibre and fibre lamination in prosthetics and orthotics: Some basic theory and practical advice for the practitioner. Prosthet Orthot Int. 1995;19(2):74-91. [PMID: 8570384]

7. Rosenberg RJ, Terry R. Use of copolymer for interfaces in all levels of prosthetic applications. J Prosthet Orthot. 1999; 3(1):22-25. DOI:10.1097/00008526-199000310-00007

8. Schuch CM. Thermoplastic applications in lower extremity prosthetics. J Prosthet Orthot. 1990;3(1):1-8. DOI:10.1097/00008526-199000310-00004

9. Cochrane H, Orsi K, Reilly P. Lower limb amputation. Part 3: Prosthetics-A 10 year literature review. Prosthet Orthot Int. 2001;25(1):21-28. [PMID: 11411001] DOI:10.1080/03093640108726564

10. ASTM Standard D-638, 2008. Standard test method for tensile properties of plastics [Internet]. West Conshohocken (PA): ASTM International. Available from: http://www.astm.org/.

11. ASTM Standard D-6110, 2008. Standard test method for determining the Charpy impact resistance of notched specimens of plastics [Internet]. West Conshohocken (PA): ASTM International. Available from: http://www.astm.org/.

12. ASTM Standard D-256, 2006a. Standard test method for determining the Izod pendulum impact resistance of plastics [Internet]. West Conshohocken (PA): ASTM International. Available from: http://www.astm.org/.

13. Smit RJ, Brekelmans WA, Meijer HE. Predictive modelling of the properties and toughness of polymeric materials. Part II: Effect of microstructural properties on the macroscopic response of rubber-modified polymers. J Mater Sci. 2000; 35(11):2869-79. DOI:10.1023/A:1004763606229

14. Klompen, ETJ. Quantitative prediction of long-term failure of polycarbonate. In dissertation: Mechanical properties of solid polymers: constitutive modelling of long and short term behavior [dissertation]. [Eindhoven (the Netherlands)]: Technische Universiteit Eindhoven; 2005. p. 111-24.

15. Van Melick HG, Govert LE, Meijer HE. Localisation phenomena in glassy polymers: Influence of thermal and mechanical history. Polymer. 2003;44(12):3579-91. DOI:10.1016/S0032-3861(03)00089-2 
16. VIVAK sheet [Internet]. Sheffield (MA); Sheffield Plastics Inc; 2003 [cited 2010 Jun 30]. Available from: http://www.framersbrand.com/docs/VivakDataSheet.pdf.

17. Thermoplastics for medical applications [Internet]. Wijnegem (Belgium): Orfit Industries; [cited 2010 Jun 30]. Available from: http://www.orfit.com/en/orthopedie/index.html.

Submitted for publication October 22, 2010. Accepted in revised form February, 14, 2011.
This article and any supplementary material should be cited as follows:

Gerschutz MJ, Haynes ML, Nixon DM, Colvin JM. Tensile strength and impact resistance properties of materials used in prosthetic check sockets, copolymer sockets, and definitive laminated sockets. J Rehabil Res Dev. 2011; 48(8):987-1004.

DOI:10.1682/JRRD.2010.10.0204

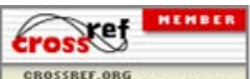

